\title{
Post-Humanistic Approaches in Archaeology
}

\author{
Kristina Jennbert (1)
}

It is a pleasure to respond to Christina Fredengren's thought-provoking keynote on post-humanistic approaches in archaeology. Her ambition is to give arguments for relational and entangled approaches and multispecies archaeology. It is a thoroughly warranted text. The political situation in the world, with increased segregation and inequality, requires action from the humanities and social sciences. Theories and methods used in archaeology are generational and time-specific, as the present is always the starting point for research. Conscious or unconscious demands in the present are incorporated, open or hidden, in our research questions. It is not remarkable that archaeological theories and methods have changed through the premodern, modern, and post-modern periods, due to ideological and political contexts, as Lori Braidotti (2OI3) outlines so well. I appreciate Fredengren's call for critical feminist posthumanism and a new materialism in archaeology as it opens up for new questions about how archaeology can work.

After a short presentation of posthuman theories and approaches and archaeological animal studies, Fredengren explores the concepts of taxonomy, hybridity, othering and killability. They are chosen to gain an understanding of how humanity and animality are produced and how to find animal agentiality. Fredengren's argument goes far beyond the traditional field of archaeological research towards more overarching existential and philosophical questions. 
In her conclusion, she gives examples of future themes important to work with: I) situated bodily hybridities, 2) writing the more-than-human into archaeological narratives, 3 ) archaeological examples of multispecies care, 4) extinction of species, 5) the importance of archaeological knowledge for giving insights into how to view the world differently. Although it is impossible to predict future research questions, her thematic proposals are interesting. They show how a researcher today sees posthumanism as a way to investigate archaeological contexts that are connected to current interests among citizens and politicians of climate and environmental issues. I totally agree with her in the reservation not to make general crosscultural comparisons and conclusions. The context of time, space and sociocultural setting can easily be forgotten when the present day is the starting point. If archaeology is to have any relevance today for understanding the origin and evolution of the globe and human societies, all parts of life on the globe must be claimed as posthuman theory and approaches call for.

With the terminology of humans, non-human animals, more-thanhumans, there is a possibility to embrace all kinds of beings in the world and the boundary crossings in the time-setting and thus to work towards a non-anthropocentric ontology. However, archaeology and zooarchaeology generally share a very anthropocentric ontology. Moving from perceiving animals as objects to acknowledging them as subjects gives new perspectives on interactions between humans and animals. Therefore, the focus on the animal itself for understanding the agency of different kinds of animals, and with or against them, is groundbreaking within the field of archaeology and zooarchaeology. Like Fredengren I would put forward the 'animal turn' as an important aspect of the posthumanistic movement. In the following, I will give some examples along these lines from my own research on pre-Christian archaeological contexts and ethics in archaeology that are connected to posthuman approaches and multispecies archaeology. Before summing up, I would like to highlight research projects in historical ecology that provide some further perspectives on current societal demands that relate to posthumanism.

What is a human, and what is non-human animal? And what attitudes to non-human animals can we see in a long-term perspective? Do certain humans and non-human animals have greater value than other humans and non-human animals? Of course, it is important to have a sense of the past and of different cultural norms and values when working with humananimal relations and perspectives on the Anthropocene. Human relations to animals are specific to each time and culture. We may assume that attitudes to animals are related to their practical utility and have to do with how they are tended. Even stocks of game animals need to be looked after if hunting is to be sustainable in the long term. Animals have been treated 
according to human needs but also according to how people have related the animals to themselves. The 'animal turn' (Ritvo 2007) highlights how structures of power deeply affect the human-animal relationship and enable radical non-anthropocentric explorations. The 'animal turn' does not only include animals but locates them as key players in the myriad situations of being in, and making sense of the world (Andersson Cederholm et al. 20I4:6).

Our understanding of domestication and the construction of the wild challenges the anthropocentric interpretation of human landscapes in the long term. Were humans domesticated by animals rather than the other way around (Jennbert 20II:22)? With a posthuman approach the neversolved question of power and domestication has new fuel for alternative ways of understanding agency. Ethical questions need to be explored, giving a deeper understanding of human-animal relationships.

As a result of my previous exploration of the relationship between humans and animals based on archaeological material, osteological analyses, and Old Norse texts, I am convinced that the power structures of the time resulted in certain humans and certain animals having greater value than other humans and animals, and that this goes far back in time. They were treated differently from other humans and animals. The asymmetric structural relations between humans and animals were a recurring theme in the rituals, be it funerals or rituals in wetlands. There are more issues to address in pre-Christian Scandinavian archaeological contexts. The shaping of powerful creatures in Old Norse society expands interpretations of attitudes to humans, animals, and hybrid beings. The interpretation of hybrid beings and boundaries between real and imaginary humans and animals draws on a variety of sources. Archaeozoological data from settlement sites, wetlands and burials give ideas about the economic and symbolic roles of humans and animals. Iconography and written sources offer information on imaginary animals, narratives, mythology, and heroic imagery. It looks as if nature and culture meet and mesh, as do humans and animals. The Cartesian dualism must be reconsidered in the light of anthropological and archaeological research on the social construction of 'humanimal' landscapes (Jennbert 2OII).

The long temporal perspective of archaeology gives us opportunities to distinguish how rituals with animals varied and underwent change during the Scandinavian pre-Christian era. The value of humans and animals, and humans' relations to individual species and particular animals, surely depended on power-related practical and functional purposes. The behaviour and properties of the animals, as well as their management, were embedded in a Midgard mentality. Humans, domesticated animals, and wild animals were all actors on the farm and in the landscape with its different 
biotopes. The contextual classifications of animals and humans resulted in specific attitudes towards humans and animals. Not as a group of species, but as individuals with their specific personalities.

I agree that archaeology needs to explore threats in our contemporary society. I suggest adding questions connected to urban planning, which involves all kinds of beings in the world, from the smallest microbes to humans and non-human animals. A long-term perspective on ecology and history helps in the contemporary challenges of achieving a sustainable, resilient, and less vulnerable environment. Looking back into historical and urban supply strategies is important for highlighting the scarcity of resources, the existence of social complexity and the need for technological and economic investment. Ongoing research within historical ecology succeeds in explaining the complexity of coordinating socio-ecological needs with different types of technological solutions. A cross-fertilization between American anthropology and anthropological archaeology led to the development of new academic environments with an emphasis on historical ecological analyses of socio-environmental relations (Isendahl \& Stump 20I9). For example, when Christian Isendahl (20I0) explores the agro-urban landscapes of Classic Maya he shows that we must go beyond the modernist dichotomy of urban versus rural land. The Uppåkra site and other Iron Age central places in Scandinavia, for example, might be understood in similar terms. The analogies certainly do not provide a universal interpretation of urbanism and landscapes, but they give us a tool to think about the spatial attitudes built into socially structured power relations to all those beings that lived in the landscape.

Although the concept of the Anthropocene grew out of the natural sciences, it opens for studies of social and political agency to explore the present-day human concern with the exploitation of the earth. Central to any understanding of relationships between humans and their environment is how we conceptualize the role of humans vis-à-vis the environment not only today, but in a long-term perspective. Power structures and the living conditions of humans give a situatedness for all beings in the world. Thus, the long temporal perspective of archaeology gives us opportunities to distinguish how power-related structures for humans, non-humans and more-than-humans have had many variations and have undergone changes in the course of time. Animals, other living organisms, and the landscape were evidently of as great significance for the life of humans in the deep past as they are today. The more-than-humans were perhaps as invisible in the past as they are for most people today. Without being too restricted in my own profession, I believe that archaeological knowledge and the long temporal perspective of archaeology provide insights into how to know the world differently, which is an important aspect to consider in the contempo- 
rary challenges of finding solutions to the environmental and climate crisis on earth. Posthuman critical archaeology should be seen as an important thinking tool which dissolves previous dualistic categorizations, for example the concept of nature versus culture.

\section{Acknowledgement}

English revised by Alan Crozier.

\section{References}

Andersson Cederholm, E., Björck, A., Jennbert, K. \& Lönngren, A.-S. (eds). 20I4. Exploring the Animal Turn: Human-animal relations in Science, Society and Culture. Lund: Pufendorfinstitutet. https://lup.lub.lu.se/search/publication/4882924.

Braidotti, R. 2013. The Posthuman. Cambridge: Polity Press.

Isendahl, C. 20I0. Greening the Ancient City: The Agro-urban Landscapes of the PreHispanic Maya. In: Sinclair, P., Nordquist, G., Herschend, F. \& Isendahl, C. (eds), The Urban Mind: Cultural and Environmental Dynamics, pp. 527-552. Studies in Global Archaeology. Vol. 15. Uppsala: Department of Archaeology and Ancient History, Uppsala University.

Isendahl, C. \& Stump, D. (eds). 20I9. The Oxford Handbook of Historical Ecology and Applied Archaeology. Oxford: Oxford University Press.

Jennbert, K. 20Ir. Animals and Humans: Recurrent Symbiosis in Archaeology and Old Norse Religion. Lund: Nordic Academic Press.

Ritvo, H. 2007. On the Animal Turn. Daedalus. Vol. I36(4) pp. II8-I22. 